\title{
Influence and Inspiration of Employment Situation on China' Higher Education in Food Program
}

\author{
J.-X. Sun, Shuling Wang, Ming Huang, Baowei Wang, Peng Li \\ College of Food Science and Engineering, Qingdao Agricultural University, Qing Dao, China(jxsun20000@163.com)
}

\begin{abstract}
Through the introduction of <2014 Chinese college student employment report>, the present employment status of Chinese college students in the year 2013 was understood. By analyzing the employment factors influencing college students' employment, comparing domestic and foreign food professional education and food program characteristics, the influence and inspiration on the reform of China's higher education in food program were discussed.
\end{abstract}

Keywords — employment status, college student employment report, employment factors, higher education in food program

\section{就业现状对我国食品专业高等教育的影响与启示}

\author{
孙京新 王淑玲 黄明 王宝维 李鹏
}

青岛农业大学食品科学与工程学院, 青岛, 中国

摘 要 通过介绍《2014 年中国大学生就业报告》, 了解 2013 年中国大学生就业情况。分析影响大学生就业的因素, 结合国内 外食品专业教育对比及食品专业自身的特点, 探讨了对我国食品专业高等教育改革的启示。

关键词＼cjkstart就业现状，大学生就业报告，就业因素，食品专业高等教育

\section{1. 引言}

随着高等教育的扩招, 毕业的大学生数量逐年递增, 这无疑加重了其就业难度。2014 年 6 月，《2014 年中国大 学生就业报告》正式发布, 分析了不同专业毕业生的就业 及发展状况。目前, 我国第一、二产业比较发达, 而第三 产业则相对落后。由于食品产业链条长, 与食品相关的专 业教育涉及产业领域跨度大, 食品专业教育如何适应经济 发展趋势, 根据就业形势的变化, 及时调整专业设置, 创 新课程体系, 改革传统教学模式, 以大力提高毕业生的就 业适应性, 成为紧迫的研究与实践课题。本文从分析最新 的大学生就业报告入手, 结合影响大学生就业的因素和国 内外食品专业高等教育对比, 讨论了该报告传达的一些重

青岛农业大学应用型人才培养特色名校建设工程课程建设项目 (资助号: XWLSP2013017); 山东省教学研究课题 “食品类人才国 际合作培养模式与机制的探索与实践” (资助号：2012338) 和 食品 “卓越工程师” 人才培养模式创新与实践项目 (资助号: 2012337)。
要信息对我国食品专业高等教育的启示。

\section{2014 年大学生就业报告}

第三方教育质量评估机构麦可思研究院(MyCOS)最近 正式发布了每年一度的大学生就业蓝皮书—《2014 年中 国大学生就业报告》。报告指出, 毕业半年后, 2013 届本科 生就业率最高的专业 (前 50 位) 是工学中的建筑学 (98.3\%), 最低的是物理学 (85.3\%); 月收入 (4757 元) 最高的专业 (前 50 位) 是建筑学, 其次 (4407 元) 是金 融学, 最低 (3067 元) 的是环境科学。

会计是 2013 届大学毕业生毕业半年后就业比例最高 的职业, 其中, 本科毕业生从事会计类职业的就业比例为 4.6\%。同时, 2010 届本科毕业生毕业三年内职业转换率高 的专业中, 最大的是外国语言文学类和轻工纺织食品类, 有 $45.0 \%$ 的人转换职业后从事其他; 2010 届本科毕业生毕 业三年内转换入最多的职业是销售, 2013 届大学毕业生最 重要的核心知识是销售与营销知识, 然而毕业生在大学学 到的销售与营销知识难以满足实际工作需要, 满足度低, 
是各项核心知识中满足度最低的一项。

2013 届大学生毕业时对基本工作能力掌握的水平均低 于工作岗位要求的水平。从全国来看, 2013 届大学生毕业 半年内有 $34 \%$ 发生过离职, 其中高职高专为 $43 \%$, 本科为 24\%。工作与自己的职业期望值不一致可能是造成毕业生 离职的主要原因。2010 届毕业三年内一直为一个雇主工作 的本科生, 月收入最高; 毕业三年内就职过的雇主数越多, 其月收入就越低 ${ }^{[1]}$ 。

通过分析该报告得出, 工学专业和经济学专业是就业 率和收入较好的专业门类, 而销售是毕业生从事的主要职 业; 当前大学生某些知识能力不足, 比如销售和营销知识 以及对基本工作能力的掌握水平等。报告在分析就业数据 的同时也对大学专业教育提出建议和要求。

\section{3. 影响大学生就业的因素}

\section{1 主观因素}

\section{(1) 自身能力的不足}

长期的应试教育模式使得大学生形成了重书本知识、 轻实践操作的惯性学习方式。自身知识储备量少, 能力不 突出, 综合素质不高, 这种自身条件的限制和需求之间发 生冲突, 使得自身能力不能满足用人单位的需求 ${ }^{[2]}$ 。

(2) 不正确的择业观

择业观直接影响和决定大学生的择业行为, 正确的择 业观对指导大学生正确地评价、定位和选择职业至关重要。 多项调查报告表明, 不愿到民营或其它非公有制企业就业, 热衷于公务员单位是大学生不正确择业观的主要表现; 其 它表现还有诸如就业地域选择聚局限在在沿海一带或经济 发达的地区, 对西部地区、偏远地区和农村不感兴趣甚至 排斥以及有好的待遇和好的工作环境等。以上情况说明大 学生自我期望值过高, 而实际上能满足刚毕业大学生就业 愿望以供选择的单位就相对不足 ${ }^{[3]}$ 。

\section{2 客观因素}

\section{（1）巨大的就业竞争压力}

首先, 由于体制改革、产业转型及社会变迁造成大量 的下岗人员, 社会失业率居高不下, 失业人员的再就业, 会加剧城乡就业岗位的紧缺局面; 另一方面, 大量农村剩 余劳动力在逐渐加快的农村城镇化进程中不断涌入城市, 进一步争夺了城镇的就业机会。因此有限的就业岗位根本 无法满足日益增多的大学生的就业需求 ${ }^{[3]}$ 。其次, 区域结 构性矛盾是造成大学生 “就业难” 的根本原因。我国经济相 对发达的东部地区则出现大量学生无法就业的现象。最后,
大学生就业难是高等教育规模扩张不可避免的现象。

（2）结构性失衡与模式僵化的大学教育

当前, 我国高校的专业结构和课程体系设置还不能很 好地适应市场经济的需要。随着社会的不断发展变化和产 业链的不断延伸, 出现了许多前所未有的新经济业态, 由 此产生了很多新的行业和职业。教育必须及时作出变革, 通过不断建立新兴学科, 淘汰过专业才能适应市场的需要。 我国由于一些制度或政策上的原因, 导致高校学科与专业 设置、课程体系、教学方法等与社会需求脱节严重, 高校 培养的学生不能有效应对市场的挑战。各高校专业重复现 象严重, 教学模式僵化, 缺少差异性和特色, 无法与市场 需求有效对接, 进一步加剧了部分专业毕业生的就业难度。

\section{4. 国内外食品专业高等教育对比}

4.1 我国高校食品及相关专业设置、课程安排的问题

我国高校食品及相关专业设置狭窄, 且局限在面向第 二产业的加工业领域, 事实上, 食品产业链条很长, 涉及 范围很广, 无其随着未来经济结构调整和产业结构升级, 第二产业比重将会大大降低, 第三产业如围绕食品的服务 业会迅猛发展, 因此, 现有的食品及相关专业设置不能很 好地适应未来产业发展趋势和相应的社会人才需求 ${ }^{[4]}$ 。另 一方面, 我国高校食品及相关专业课程设置的特点首先是 国家通得太死, 这表现在最近几年我国进行的食品教育专 业规范标准和专业认证规定的课程总学分（大于 180）偏 多, 课程知识点太细 ${ }^{[5]}$, 全国各高校尤其是地方院校基于 本地优势和特色而欲改革的空间不大, 如基础课一般注重 化学类课程, 专业基础课则涉及生物或生命科学以及工程 原理等课程, 两者共计近 20 门, 因而开设得过多; 其次是 重理论而轻实践, 重知识而轻能力, 这表现在部分实践性 较强的课程如实验或实习环节, 设置门类和所占课时偏少, 学生所学知识不能够通过实践而转化为自身的能力; 另外, 学生可自由选择的课程少、新课少, 自由选课的余地不大, 课外活动不丰富, 这在很大程度上限制了学生个性的发展、 能力的拓宽和素质的提升。

4.2 美国高校食品专业设置及课程安排的特色 (以美国密 歇根州立大学为例）

美国密歇根州立大学下设两个食品相关系部: 食品科 学与人类营养学系以及农业、食品与资源经济学系, 均隶 属于该校农业与自然资源学院 ${ }^{[6]}$ 。

食品科学与人类营养学系下设食品科学专业、食品加 工技术专业以及食品营养学专业三个专业。农业、食品与 
资源经济学系下设:食品行业管理专业、农业产业化管理专 业以及环境经济学专业三个专业。

美国密歇根州立大学的专业课程多为入门级的概括性 知识而非深入的理论; 相对重视专业选修课程, 并具有各 自专业的优势。以营养学为例, 该大学将其单独设置专业 而我国高校（除医学领域）一般仅作为一门课程；其食品 科学专业和食品加工技术专业的课程设计与我国大学食品 科学与工程专业科学方向的课程基本等同, 但其农业、食 品与资源经济学系各专业( 目前在国内还没有如此细致的 专业划分) 的课程则远远超出了我国大学食品专业的设置 及课程安排 ${ }^{[6]}$ 。

在美国, 高校对课外实践有着明确的学分规定, 即规 定学生利用寒暑假进行专业课程的实习, 拿到相应的学分 必须由实习单位出具证明方可, 学生也可在学期中利用课 余时间进行兼职实习，学校并不用正常的时间单独为学生 安排除实验外的实践环节。

美国高校重视学生的自我发展, 各高校并没有统一的 教学模板; 精心的专业设置及针对性的课程安排, 可使每 位学生根据自己的个体情况选择适合发展的方向。

\section{5. 对食品专业高等教育的影响与启示}

目前, 我国高校食品专业教育侧重于食品科学, 食品 工程相对较弱，而从就业报告看，工程类人才就业率最高, 因此，应该大力加强工程类教育。工程类教育主要面向第 二产业，但随着产业结构升级，与食品相关的服务业如销 售、管理、经营类人才将成为社会需求的方向（见前就业 报告和美国高校食品专业设置)。因此，我国食品专业教育 也应加强与食品运营与管理有关的教育。未来的食品产业 化和现代化要求规范化的运营管理来保证食品品质、食品 安全以及食品贸易的顺利发展。食品相关专业的学生既要 精通食品工程技术, 还要拥有食品运营与管理方面的知识 和能力。因此, 对我国高校食品相关专业的设置和课程体 系的科学构建将成为实现未来人才培养目标的关键。具体 应进行以下几方面改革:

\section{1 强化工程实践教育 ${ }^{[7]}$}

我国高校食品专业教育的课程安排应特别注重课程的 工程性和实用性。适当加大工程实践如食品机械与包装设 计、食品工程原理设计、食品新产品设计与综合开发、食 品工厂设计等设计类教学环节在整个课程安排中的比例。 积极建设校内外工程实践教学基地，强化食品技能综合实 习; 鼓励学生充分利用假期从事专业社会实践活动; 针对 学生毕业后的工作岗位环境实际条件, 成立形式多样的工
程实践俱乐部, 强化应用训练, 使学生理论结合实际。通 过以上多措并举，逐步提高大学生提出问题、分析问题、 解决问题的工程实践能力与综合素质, 增强其毕业后的社 会适应性。

\section{2 构建食品教育核心课程, 重视食品运营与管理教学}

我国高校食品专业教育在现有基础上应进一步减少总 学分, 国家层面上由专业规范标准和专业认证规定的课程 应为食品核心课程, 可占总学分的一定比例如 $60 \%$, 其余 40\%学分的课程应由各高校因地制宜, 自主设置, 只有这 样才能真正形成各具特色的食品专业教育。社会对食品运 营与管理方面的人才需求量越来越大, 建议各高校在食品 专业教育中增加食品运营与管理专业或方向, 加大食品运 营与管理必修或选修课程的比例。在教学方面, 应倡导食 品专业与经管专业、传媒专业交叉联合办学, 适当增加一 些特色课程, 如食品产业链管理、市场学、财会学、食品 认证、食品产业与贸易政策、食品写作等 ${ }^{[8]}$ 。重视与强化 食品运营与管理方面的课程设计或毕业设计, 针对学生的 兴趣爱好确定比较广泛的设计题目, 突出个性化、多样化、 创新性特色，如与食品运营与管理实践教学有关的设计主 题可涉及食品销售方案设计、食品企业管理规范设计、食 品产品标识或广告设计、食品造型与摄影设计、食品质量 安全物联网设计、食品营养配餐和餐饮管理软件设计等方 方面面。只有这样，才能培养适应我国经济与社会发展需 要的, 为食品产业化和国际化服务的复合应用型人才。

\section{6. 致谢}

对麦可思研究院提供的报告以及于林宏对稿件格式的 整理编排表示感谢。

\section{参考文献(References)}

[1] MyCOS institute. Chinese college graduates employment annual report (2014). Beijing: Social Academic Press, 2014.

[2] Y. D. Chen. Strategies to solve employment frustration facing chinese graduates. Journal of Enshi Technical College, no. 2, pp.94-96, 2009.

[3] L. F. Wang, Y. J. Wang and Y. H. Cheng. Analysis of the cause for "difficulty in employment" of current college graduates. China Market, no. 9, pp.57, 2006.

[4] J. X. Sun. Analysis of the employment and social demand of Shandong province undergraduates majoring in food science and engineering. Higher Agricultural Education, no.9, pp.85-88, 2009.

[5] W. S. Xia. Specifications for food science and engineering major Changchun: Documents from MOE Teaching sub-Committee 
Responsible for the Construction of Food Science and Engineering Program, 2007.

[6] J. X. Sun, M. Huang and Y. X. Zhang, et al. Contrast and enlightenment of programme set-up and curriculum arrangement of food specialty in American and Chinese universities - taking michigan state university as an example. Higher Education Forum, no.2, pp.123-126, 2011.
[7] J. R. Can and W. L. Zhang. Comparative studies on food science and engineering higher education between China and Germany. Journal of Jiangsu University: Higher Education Study Edition, vol. 27, no. 3, pp. 24-28, 2005.

[8] J. X. Sun, B. W. Wang, Q. J. Sun, et al. The necessity of setting operation and management direction in food major of higher colleges in China. China Education of Light Industry, no. 6, pp. 12-14, 2010. 